\title{
Research on Failure Modes and Key Parameters of Corrugated Steel Shear Walls
}

\author{
CAO Qiang ${ }^{1, \mathrm{a}}$, HUANG Jingyu ${ }^{1,2, \mathrm{~b},{ }^{*}, \text { WANG Peng }}{ }^{1}, \mathrm{ZHANG}_{\text {Long }}{ }^{1}$, WU DI ${ }^{1}$, CHEN Heng $^{1}$ \\ and ZHANG Yansheng ${ }^{1}$ \\ ${ }^{1}$ Department of Building Engineering, Tongji University, Shanghai, 200092, China \\ ${ }^{2}$ National Maglev Transport Research Center, Tongji University, Shanghai, 201800, China \\ acaoqiang6188@sina.com, ${ }^{b}$ hymaglev@sina.com \\ (Supported by the Shanghai science and technology talent project (Grant No. 13XD1401800))
}

\begin{abstract}
The corrugated steel plate shear wall is an effective and economical lateral load resisting system. And the thin steel plate is easy to buckle. And it is necessary to use much more thickness or ribs to prevent the buckle at out of plane direction, which is not economical or complicated to construct. A number of corrugated shear walls are analyzed by nonlinear static pushover analysis method. And failure modes, buckling, the ultimate capacity, and shear force-drift curves are studied. The results showed that the corrugated steel plate can be designed according to the failure modes, in order to have a desirable failure mode that the corrugated steel plate yield before buckling.
\end{abstract}

\section{Introduction}

Experimental and numerical studies conducted in the past three decades have demonstrated that a steel plate shear wall is an effective and economical lateral load resisting system against both wind and earthquake forces. It is easy for the flat steel plate to buckle out of plane buckling, and bearing capacity reduce with the increase of out of the plane the deformation. More thickness is guaranteed to reach the design strength, so it is not economic to be applied in the tall building structures. And in the process of buckling, large sound occurs. In order to prevent the loss of strength due to buckling, steel plate with robbers perfectly solve the problems of out of plane buckling, with high strength. However, the steel plate shear walls provide much more process and difficulties in the construction.

There is waves in the corrugated steel shear walls. It is the special stricture that increase the height of the cross section, then increase the inertia moment of the cross section. The special steel structure not only effectively restrict the out of plane structure buckling and the large sounds of in the process of buckling, but also are more convenient to construct. So the corrugated steel shear walls have potential that become economical alternatives of lateral load resisting systems, especially in the high rise building structure, with both the advantages

\footnotetext{
*Corresponding author:hjymaglev@sina.com
} 
of the flat steel plate and the steel plate with ribs.

At present, the researches mainly focus on the post buckling performance of corrugated steel shear walls ${ }^{[1]-[2]}$, which are used in multi-storied buildings and bridge structures. In order to make full use of the buckling of corrugated plate, the domestic and foreign scholars have carried out extensive research on the buckling behavior of corrugated steel plate. The initial research was initiated by Easley and McFarland. Since then, Elgaaly, El-Metwally in USA, Abbas and Sayed-Ahmed in Canada have done a lot of theoretical and experimental studies on the buckling characteristics and strength of deformed steel webs. At present, there are few researches on the application of the corrugated steel plate in the high-rise building, and lack of the corresponding experimental data. In view of the excellent performance of corrugated steel, it is necessary to study the performance of corrugated steel plate shear wall in high-rise buildings ${ }^{[3]-[4]}$.

\section{Numerical Modeling and Analysis of Steel shear Wall}

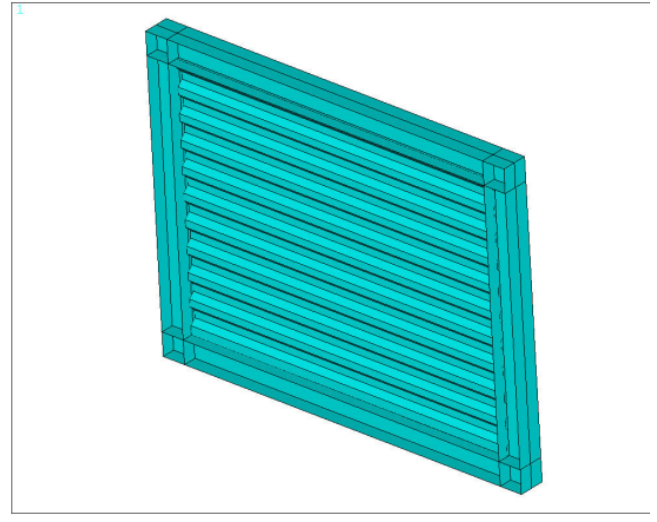

Fig.1 the schematic corrugated steel shear wall with corrugated waves

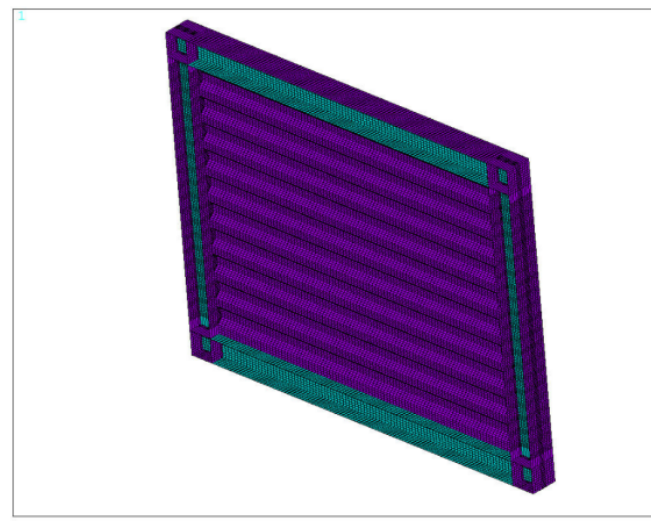

Fig.2 meshing configuration of steel shear wall with corrugated waves

The numerical analysis were performed on one story and one span of $3300 \mathrm{~mm}$ width and $2500 \mathrm{~mm}$ height. The section sizes of the boundary element columns and beams are HW $300 \times 300 \times 10 \times 15$ and HW350 $\times 350 \times 12 \times 19$ respectively. The infill plate in this wall was trapezoidal corrugated plate, rigidly connected to the frame. And the corrugated plates shows in fig. 1 .
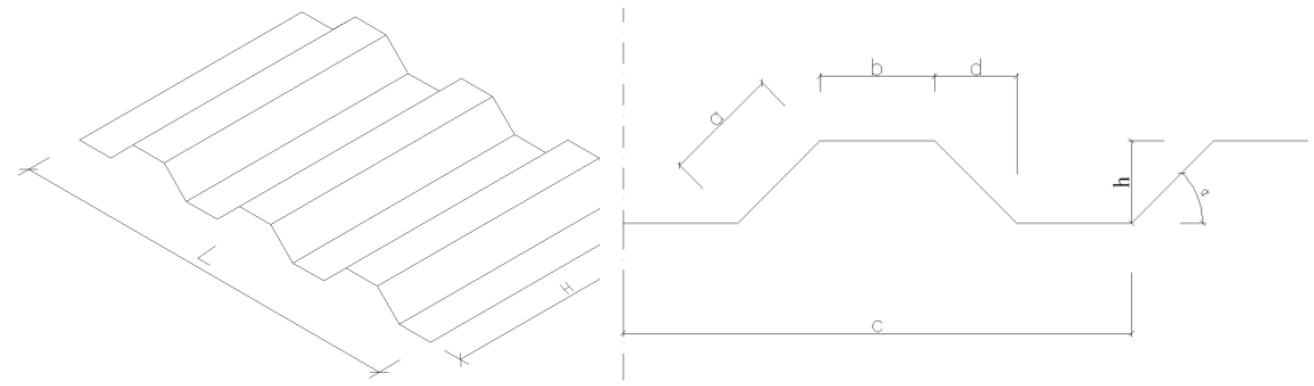

Fig.3 geometric properties of cross section of corrugated plates

Geometry and meshing configuration of these walls are shown in Fig.1 and fig2. And the geometric properties of cross section of corrugated plates are shown in fig.3. The whole 
structure was supported by fixations on the bottom of the column, giving simple support in the out-of-the plane direction for the prevention of out-of-plane displacement all around the frame. In these models, an elastic-plastic material modal was multilinear kinematic hardening modal, assumed with a yield strength value of $360 \mathrm{MPa}$ corresponding to a strain value of $0.18 \%$, a ultimate strength value of $530 \mathrm{MPa}$, corresponding to a strain value of $4.46 \%$, a necking value of $416 \mathrm{MPa}$ corresponding to a strain value of $7.34 \%$, a modulus of elasticity of $200 \mathrm{GPa}$, and a poison ratio of 0.3 . Additionally, geometric nonlinearity was used because of the large displacement.

Tabel.1 Failure Modes Of Corrugated Steel Plate Shear Wall

\begin{tabular}{|c|c|c|c|}
\hline $\begin{array}{c}\text { Thickness } \\
(\mathrm{mm})\end{array}$ & Failure Modes & $\begin{array}{c}\text { Critical } \\
\text { buckling stress } \\
(\mathrm{kN})\end{array}$ & $\begin{array}{c}\text { Maximum } \\
\text { load } \\
(\mathrm{MPa})\end{array}$ \\
\hline 0.5 & buckling in corrugated plate & 173.8 & 234.1 \\
\hline 1 & buckling in corrugated plate & 793.9 & 802.1 \\
\hline 2 & buckling in corrugated plate & 1479.5 & 1428.9 \\
\hline 4 & strength failure in the corrugated & 2518.0 & 2737.5 \\
\hline 6 & shear wall & 3763.8 & 4206.4 \\
\hline 8 & strength failure in the column & 6183.0 & 5721.9 \\
\hline 10 & strength failure in the column & 8284.0 & 7029.7 \\
\hline
\end{tabular}

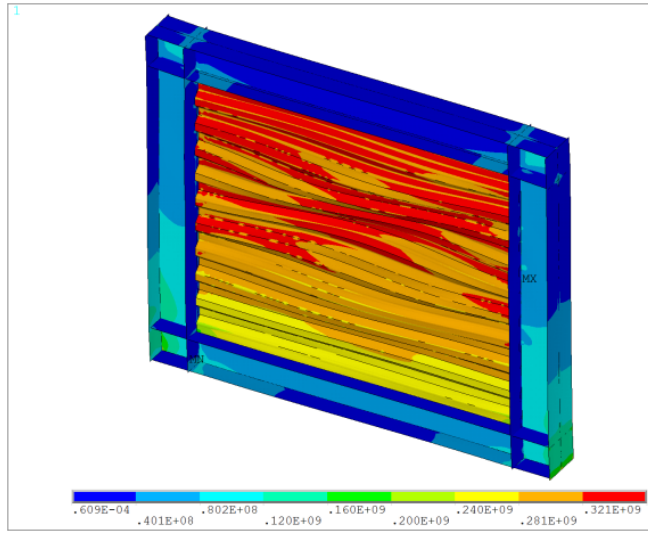

Fig. 4 buckling in corrugated plate with $2 \mathrm{~mm}$ thickness of corrugated shear steel wall

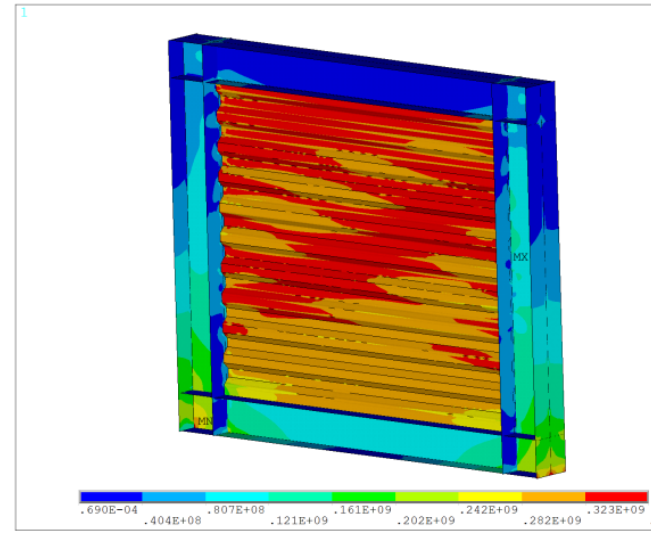

Fig.5 strength failure in the corrugated shear wall with 4 $\mathrm{mm}$ thickness of corrugated shear steel wall

According to the results shown in table.1 for corrugated plates with seven different thickness, we can know that it is the thickness that plays a key role in the failure modes of the corrugated shear walls. The failure modes change from buckling in corrugated plate's modes, strength failure in the column mode to strength failure in the column with the increase of the thickness of corrugated walls. The ultimate bearing capacity and critical buckling stress increase with the thickness of walls.

When the wall thickness is small, the failure modes are wall buckle, and the maximum stress of the wall occurs near the corner of the frame, shown in fig.4. With the increase of the thickness, the frames are in elasticity all the time. And the-out-of plane deformation is 
gradually reduced. When the thickness increase to a certain degree, the corrugated steel wall do not buckle. And the stress exceed the yield strength of the corrugated plates. And the maximum stress of the wall occurs near the corner of the frame, shown in fig.5. When the thickness continues to increase, the corrugated walls in the yield stage do not buckle any more. However, the flange or the web of frame begin to occur wave deformation, that is to say, the frame buckle, shown in fig. 6.

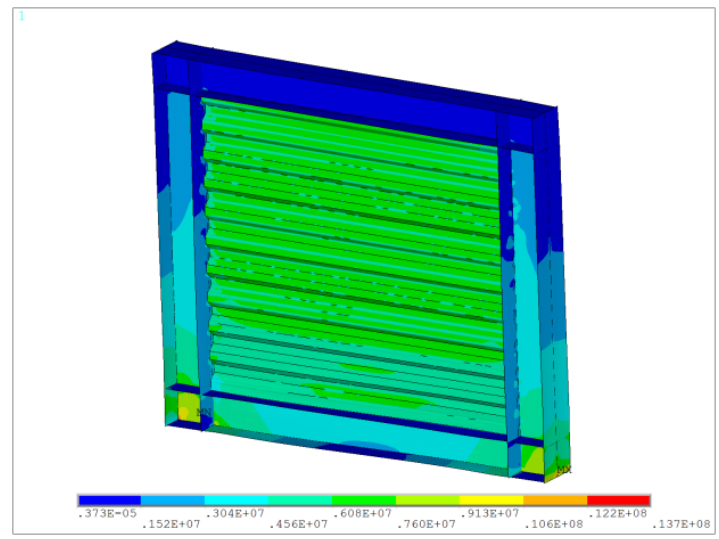

Fig. 6 strength failure in the column with $8 \mathrm{~mm}$ thickness of corrugated shear steel wall

The above results verify that the corrugated shear steel walls can yield before buckling when the thickness reach a certain value.

\section{Evaluation of the Parametric Study Results}

\subsection{The Corrugation thickness Effect of Infill Corrugated Plates}

In this part, the effect of some geometric properties in the corrugated steel shear walls were investigated, such as the thickness of corrugated plate, depth, wave height of plate, and length of wave. The results of these parameters show in detail.

Table.2 The Thickness Effect Of The Corrugated Plate

\begin{tabular}{ccccc}
\hline \hline $\boldsymbol{t}_{\boldsymbol{w}}$ & $\boldsymbol{a}$ & $\boldsymbol{h}$ & $\boldsymbol{b}$ & $\boldsymbol{L}$ \\
\hline $0.5,1,2,4,6,8,10$ & 50 & 50 & 240 & 3300
\end{tabular}

The thickness that are considered for the study of effect of thickness on trapezoidal corrugated plates are $0.5,1,2,4,6,8$ and $10 \mathrm{~mm}$ respectively. The geometric properties of the applied plates are showed in table 1 . 


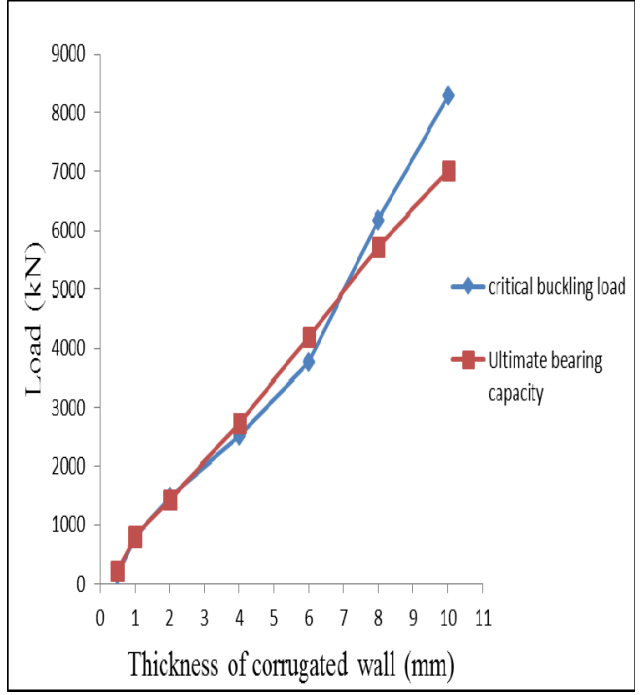

Fig.7 Critical buckling load and ultimate capacity load curves with different thickness

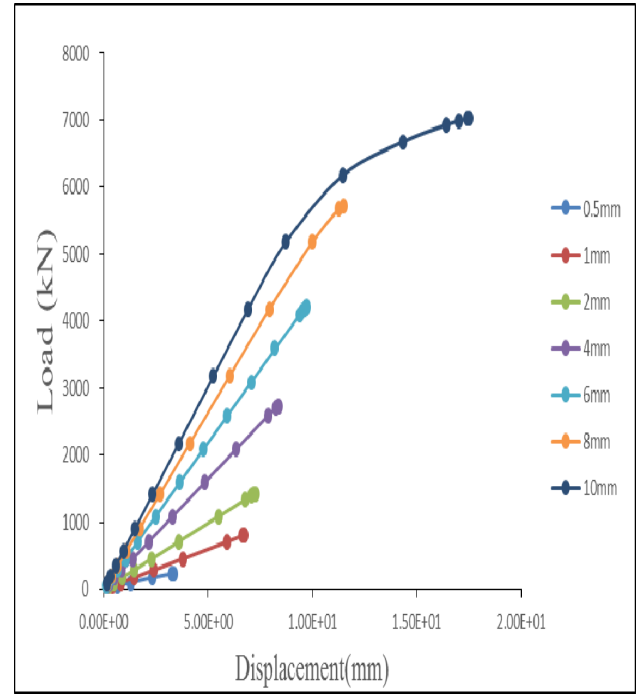

Fig.8 Load-displacement load curves with different thickness of corrugated shear wall

According to the results shown in Figs.7 for corrugated plates with seven different thickness, the ultimate bearing capacity and critical buckling load increase with the increase of the thickness of corrugated shear walls. Also in these walls, out of plane deformation of the wall occurs a plastic hinge formation in nearly all beam to column connections when the plate thickness increases. And the stiffness increase with the thickness of corrugated shear walls, shown in fig. 8 .

\subsection{The Corrugation Length Effect of Infill Corrugated Plates}

The corrugation depth is one of the parameters that increased the lateral stiffness of the corrugated steel plates. In this part, to study the effect of corrugation depth on corrugated plates, five specimens with different corrugation length of 2500, 3000, 3500, 4000, 4500, and $5000 \mathrm{~mm}$ are used. The geometric characteristics of these plates are shown in table 3 .

Table 3 Geometrical Dimensions Of Corrugated Plates With Different Corrugation Length

\begin{tabular}{cccccc}
\hline \hline$L$ & $\boldsymbol{a}$ & $\boldsymbol{t}_{\boldsymbol{w}}$ & $\boldsymbol{h}$ & $\boldsymbol{b}$ & $\boldsymbol{H}$ \\
\hline $2500,3000,3500,4000,4500,5000$ & 50 & 4 & 50 & 240 & 3000
\end{tabular}

To study the effect the corrugation depth in trapezoidal corrugated plates, six specimens and their characteristics are demonstrated in table 4.

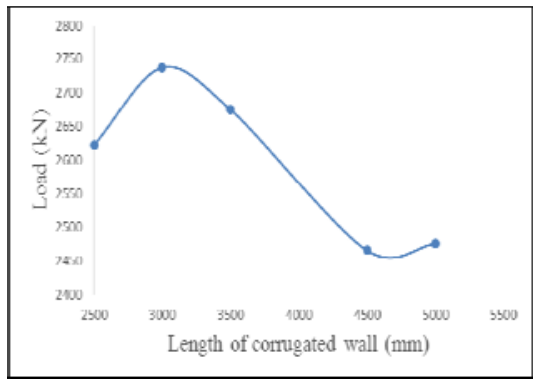

Fig.9 Ultimate capacity load curves with different length of corrugated shear wall

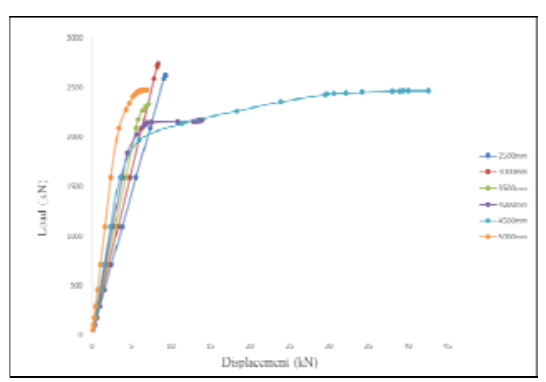

Fig.10 Load-displacement load curves with different length of corrugated shear wall 
The results of these specimens under in plane loading are shown in figs. 9 and fig. 10. These results demonstrate that with an increase in corrugation length, the ultimate bearing, increased significantly before the thickness of $3000 \mathrm{~mm}$, and when the ultimate bearing capacity decrease largely when the thickness exceed over $3000 \mathrm{~mm}$. The stiffness of the walls increase with the increase of thickness of steel plate wall. According to this figure, the stiffness increase with the increase with thickness of corrugated steel plate walls, while the trend of ductility of shear walls is opposite shown in fig. 10.

\subsection{The Corrugation Height Effect of Infill Corrugated Plates}

In this part, four specimens of specimens of corrugated plate were used for studying corrugation length effect. The geometric characteristics of these plates are shown in table, where $H$ is the corrugation height of plates and table 4 show geometrical dimensions of corrugated plates with different corrugation length $(\mathrm{mm})$.

Table 4 Geometrical Dimensions Of Corrugated Plates With Different Corrugation Length

\begin{tabular}{cccccc}
\hline \hline$H$ & $\boldsymbol{a}$ & $\boldsymbol{t}_{\boldsymbol{w}}$ & $\boldsymbol{h}$ & $\boldsymbol{b}$ & $L$ \\
\hline $2500,3000,3500,4000,4500$ & 50 & 4 & 50 & 240 & 3000
\end{tabular}

Figs.10 show that for corrugated plates the ultimate bearing increase with increases in the corrugation length and the walls lost bearing due to global buckling failure. The stiffness performance of corrugated plate shows that the initial stiffness do not change with the corrugation height. But the ductility of the wall changed considerably.

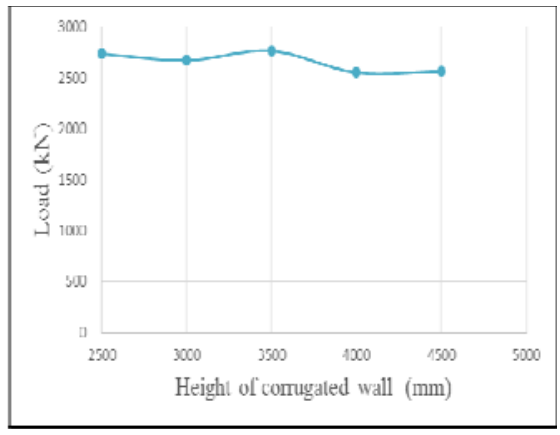

Fig.11 Ultimate capacity load curves with different height of corrugated shear wall

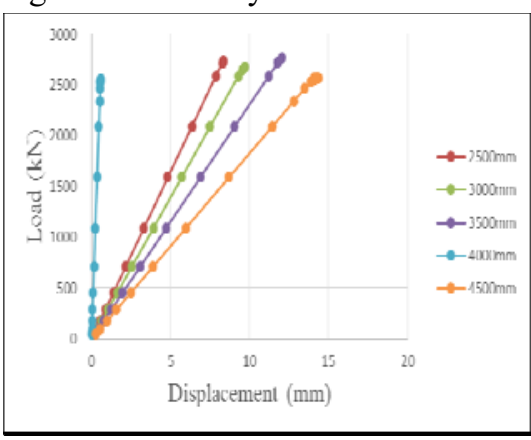

Fig.12 Load-displacement load curves with different height of corrugated shear wall

\section{Summary}

In this paper, an investigation into the failure modes and geometric characteristics of corrugated one-story steel shear wall when subject to uniform lateral load was carried out. The following results were obtained:

1. Within the increase thickness of corrugated plate thickness in steel shear walls, the corrugated steel shear walls have three different failure modes, buckling in corrugated plate, strength failure in the column and strength failure in the column. The ultimate bearing and critical buckling stress increase with the increase with corrugated plates.

2. The corrugated shear steel walls can yield before buckling when the thickness reach a certain value.

3. The other parameter investigated in this paper was the corrugated length. The 
corrugated depth has greater effects on stiffness, ultimate bearing.

4. The study of corrugation height in the corrugated plates showed that the ultimate bearing do not change with increases in the corrugation height, But the ductility of the wall changed considerably.

\section{References}

1. Seilie I F,Hooper J D. Steel plate shear walls: practical design and construction [J]. Modern Steel Construction, 2005: 29-33.

2. Ericksen J, Sabelli R.A closer look at steel plate shear walls [J]. Modern Steel Construction, 2008: 63-67.

3. Zhu Wei, Mei Hongxian, Analysis on lateral force performance of corrugated steel plate shear wall [J]. Planning and Design, 2013 [5]:20-24.

4. S.A.Edalati, Y.Yadollahi, Numerical study on the performance of corrugated steel shear walls [J] Wind and Structures, 2014 [4]:405-420. 